\title{
Screening of Antibiotic Producing Actinomycetes from the Sediments of Undisturbed Forest Areas and Its Hyper Activity after Mutation
}

\author{
P.Ashok Kumar and P.Karpagam
}

\begin{abstract}
Wide and uncontrolled usage of antibiotics has made the pathogens to become resistant to currently used antibiotics. There is an urgent need for development of a new drug or a highly active molecule for controlling antibiotic resistant strains. In this study 32 strains of Actinomycetes were isolated and subjected to primary screening by giant colony method against Bacillus subtilis, Escherichia coli, Pseudomonas aeruginosa and Aeromonas hydrophilia. The secondary screening was carried out by fermentation process. Antibacterial activity was evaluated by well plate method. The extract of isolates was subjected to well plate method against pathogenic bacteria. B. subtilis and E. coli were highly inhibited by AK1 isolate. Other isolates showed limited inhibition of bacteria. The AK1 isolate was mutated by UV irradiation. The mutants differed from the wild parent in reduced growth rates, changes in the shape and size of the colony, sporulation level, antibiotic activity and variation in the color of the mycelium. The zone of inhibition was higher with Actinomycetes AK1 inoculated plates. The secondary metabolite production was enhanced by UV mutagenesis when compared to wild type. Actinomycetes may produce different molecule that can inhibit different types of pathogens, however efforts like strain development can be done to produce new bioactive components against multidrug resistant bacteria.
\end{abstract}

Index Terms - Aeromonas hydrophilia, Antibiotic producing Actinomycetes, Multi drug resistant bacteria, Pseudomonas aeruginosa.

\section{INTRODUCTION}

The history of the discovery of new drugs shows it comes from natural sources (Bevan et al., 1995). Agro industrial residues are composed of complex polysaccharides that support the microbial growth for the production of useful products (enzymes, organic acids, drugs, etc.) (Javed et al., 2013). The antimicrobial resistance is presently an urgent focus of research and new bioactive compounds are necessary to combat the pathogens (Freire-Moran et al. 2011). The development of resistance to multiple drugs is a major problem in the treatment of infections by pathogenic microorganisms (Boucher et al., 2009). New strain development for antibiotic

Manuscript received August 29, 2016.

Dr.P.Ashok Kumar is with the Department of Microbiology, Sokoto State University (SSU), Sokoto, Nigeria

P.Karpagam was with Department of Microbiology, Sokoto State University (SSU), Sokoto, Nigeria. production has been an essential prerequisite for scale up of antibiotic production and also for search of new antibiotics (physical and chemical mutagenesis). In general, strain improvement is considered as one of the main factors involved in the achievement of higher titers of industrial metabolites $\mathrm{CHu}$ and Ochi. 2001). Random mutagenesis and fermentation screening have been reported as an effective way to improve the productivity of industrial microbial cultures (Medema et al., 2011). Antibiotics, because of their industrial importance, are the best known products of Actinomycetes (Nanjwade et al., 2010). Improvement of microbial strains for over production of industrial product has been the hallmark of all commercial fermentation processes.

The prevalence of bacterial pathogens resistant to the available antibiotics has been increasing over the past several decades (Kumar et al., 2012). To prevent exponential emergence of microorganisms becoming resistant to the clinically available antibiotics already marketed, periodic replacement for existing antibiotics is necessary (Ilic et al., 2007). Actinomycetes have been and remain the most fruitful source of microorganisms for all types of bioactive metabolites, including agro active type. Over one thousand secondary metabolites from Actinomycetes were discovered during 1988-1992 (Doumbou et al., 2001). Secondary metabolites are primarily aimed at discovering novel secondary metabolites, which can counteract resistance from pathogens and circumvent side effects that are typically associated with most indispensable therapeutic drugs (Bapela et al., 2008). About 70\% of all known drugs have been isolated from Actinomycetes bacteria of which $75 \%$ and $65 \%$ are used in medicine and agriculture, respectively (Tanaka and Omura, 1993). Industrial development practice includes natural selection, mutation and protoplast fusion (Smith, 1986). The UV radiation is the most convenient of all mutagens to use, and it is also very easy to take effective safety precautions against it. It gives a high proposition of pyrimidine dimmers and includes all types of base pair substitutions (Rani et al., 2012). This work, describes the isolation of Actinomycetes strains having antimicrobial activities from the soil samples of Asella town, Ethiopia and the mutational analysis using UV treatment, to enhance the production of secondary metabolites from screened Actinomycetes. 


\section{MATERIALS AND METHODS}

\section{A. Isolation of Actinomycetes}

In this investigation, samples were collected from the superficial layer of soil at a depth not exceeding $3-5 \mathrm{~cm}$ with a plastic spoon in sterile polyethylene bags, from the undisturbed forest area of Asella town, Ethiopia. Actinomycetes were isolated by using Starch Casein Nitrate (SCN) agar. Cyclohexamide and nystatin $(50 \mu \mathrm{g} / \mathrm{ml})$ were added into the medium as antifungal agent (Porter et al., 1960; Phillips and Hanel, 1950). The plates were incubated at $28^{\circ} \mathrm{C}$ for 5-10 days. Plates were checked for the growth of typical Actinomycetes colonies up to 10 days. Individual colonies with characteristics of Actinomycetes morphology were identified based on the methods described by Williams and Cross (1971). Isolated colonies were pure cultured by repeated streaking on SCN agar plates and the pure strains were stored at $4^{\circ} \mathrm{C}$ in SCN agar slants. The potent Actinomycetes were characterized by morphological and biochemical methods (Gogoi et al., 2005).

B. Giant Colony Technique for Screening of Actinomycetes for Antimicrobial Activity

All colonies of Actinomycetes isolates were streaked in a narrow band across the centers of Muller Hinton agar plates (Lazzarini et al., 2002). The plates were incubated at room temperature for 7-10 days. The test organisms were streaked from the edges of the plate to the Giant colony but not touching the colony. Again the Muller Hinton Agar plates were incubated at room temperature for 2 to 3 days. After incubation the length of growth line was measured in millimeter from the edge of the Giant colony to the tip of the growth of the test organism. The highly active isolates were inoculated into the Muller Hinton broth with $0.02 \%$ Tween 80 and $1 \%$ Glycerol and incubated at room temperature for 48 hours.

\section{Antibiotic production}

Shake flask fermentation was carried out with $250 \mathrm{ml}$ of Antibiotic production medium (soluble starch $25 \mathrm{~g}$, glucose $10 \mathrm{~g}$, yeast extract $2 \mathrm{~g}, \mathrm{CaCO}_{3} 3 \mathrm{~g}$, Trace salts solution $1 \mathrm{ml}$, distilled water 1 liter, $\mathrm{pH} 7.5 \pm 0.2$ [Trace salt solution $\mathrm{FeSO}_{4} .7 \mathrm{H}_{2} \mathrm{O}-0.5 \mathrm{~g} ; \mathrm{CuSO}_{4} .5 \mathrm{H}_{2} \mathrm{O}-0.5 \mathrm{~g} ; \mathrm{ZnSO}_{4} .7 \mathrm{H}_{2} \mathrm{O}-0.5$ $\mathrm{g} ; \mathrm{MnCl}_{2} \cdot 4 \mathrm{H}_{2} \mathrm{O}-0.5 \mathrm{~g}$ in $100 \mathrm{ml}$ of distilled water]. The flasks were shaken at $28^{\circ} \mathrm{C}$ and $160 \mathrm{rpm}$ for 5-7 days on the rotator shaker and finally the filtrate was used to test the antimicrobial activity.

Solvent extraction was performed with selective Actinomycetes spent medium using Ethyl acetate as solvent. The spent medium and the solvents were thoroughly mixed. The upper solvent layer was concentrated in vacuo to get extracted substances (Gogoi et al., 2005). The antimicrobial activity was determined by agar well plate method (Thakur et al., 2007). Antibacterial activities were tested against different bacteria like Aeromonas hydrophilia, Bacillus subtilis, E. coli, and Pseudomonas aureginosa.

\section{Mutational Analysis}

Well sporulated agar plate was selected for collecting spores. Required amount of sterile water with wetting agent like Tween 80 was added to plate. The surface of growth was gently scraped with an inoculating loop to liberate spores in the water. The suspension was poured into a sterile centrifuge tube and vigorously mixed for one to two min. The suspension was filtered through nonabsorbent cotton wool using a filter tube, to remove mycelia and agar pieces. The spore suspension was centrifuged at low speed about $5000 \mathrm{rpm}$ for $20 \mathrm{~min}$. The supernatant was discarded immediately after the centrifugation. This will prevent the detachment of pellet from the wall of tubes. The pellet was suspended with $1 \mathrm{ml}$ of sterile water.

\section{E. UV Irradiation - Mutagenesis}

The spores of highly active isolate were collected and stored in distilled water. The spores in $1 \mathrm{ml}$ of water were counted by viable plate counting method. Ultraviolet (UV) mutagenesis was carried out at a distance of $30 \mathrm{~cm}$ for $20,40,60,80,100$, 120,140 and 160 seconds (Zhang et al., 1993). Nitrosoguanidine (NTG) mutagenesis was performed according to Holmalahti et al., (1993) for 0, 15, 30, 45, 60, 75 and 90 seconds. In all mutagenesis techniques, photo-reactivation was avoided by keeping the isolated colonies overnight in the dark by wrapping the plates in aluminum foil (Held and Kutzner, 1991) and a survival rate of not more than $1 \%$ was considered. The mutated colonies were identified by the physical features of the colonies. The mutant colonies were sub-cultured (7 days, $28^{\circ} \mathrm{C}$ ) again to express and stabilize the mutants. The mutant colonies were designated as AK 1 to 5.

\section{F. Bioassay of UV Mutated Strains of AK1 isolate}

After incubation, colonies with different morphology were selected for analysis. Selected mutants survivors are patched over the surface of the antibiotic production medium and incubated for 7-9 days at room temperature in dark. To test for the antibacterial activity, Staphylococcus aureus ATCC 25923 was used as a test organism. Mueller-Hinton agar medium was used as an assay medium. The agar medium at $45^{\circ} \mathrm{C}$ was mixed with $0.1 \mathrm{ml}$ bacterial suspension containing approximately $10^{5}$ $\mathrm{cfu} / \mathrm{ml}$. The mixture was poured into $9 \mathrm{~cm}$ Petri dish and allowed to solidify. Sterile paper discs $(6 \mathrm{~mm})$ were placed on the dried surface of the medium. Each disc received $20 \mu 1$ of the culture filtrate. Petri dishes were incubated at $37^{\circ} \mathrm{C}$ for 18 hours. The inhibition zone, if any, was measured in $\mathrm{mm}$ diameter (Amade et al., 1994).

\section{RESULTS}

32 strains of Actinomycetes were isolated and subjected to primary screening by giant colony method against Bacillus subtilis, Escherichia coli, Pseudomonas aeruginosa and Aeromonas hydrophilia. The antibacterial activity was evaluated by well plate method. The zone of inhibition was higher with Actinomycetes AK1 inoculated plates. In the case of Aeromonas hydrophilia, all the isolates (spent medium and 
mycelial extract) showed limited inhibition. Bacillus subtilis and $E$. coli were highly inhibited by AK1 isolate. Other bacteria were inhibited by both spent and mycelial extract. In some cases, mycelial extract showed no activity against bacteria (Table I).

TABLE I

SCREENing Of ANTIBACTERIAl ACTIVITIES By Well Plate Method (MM)

\begin{tabular}{lcccccccccc}
\multicolumn{1}{c}{ (S - SALINE: EA - ETHYL ACETATE) } \\
Organisms & AK1 & \multicolumn{1}{c}{ AK2 } & \multicolumn{1}{c}{ AK3 } & AK4 & \multicolumn{2}{c}{ AK5 } \\
& EA & S & EA & S & EA & S & EA & S & EA & S \\
A.hydrophilia & 28 & 21 & - & - & 9 & - & 13 & - & - & - \\
B.subtilis & 24 & 18 & 11 & 23 & 15 & - & 11 & - & 14 & - \\
$\quad$ E.coli & 30 & 25 & 11 & 13 & 19 & 10 & 10 & - & 14 & 18 \\
P.aeruginosa & 15 & - & 10 & - & 14 & 20 & 10 & - & 11 & - \\
$\quad$ S.aureus & 19 & 20 & 11 & - & 11 & - & 11 & - & 11 & -
\end{tabular}

The bioassay of AK1 mutated strains were tabulated (Table III).

\section{A. Mutagenesis of AK1 isolate- UV Mutagenesis:}

The AK1 isolate was mutated by UV irradiation. The rate of mutation was parallel with the increasing exposure and was followed later by a decline. The mutants differed from the wild parent in reduced growth rates, changes in the shape and size of the colony, sporulation level, antibiotic activity and variation in the colour of the mycelium. The survival count of AK1 UV mutation was tabulated (Table. II).

TABLE II

Survival COUNT Of AK1 IsOlate AFTer Uv IRRADIATION

$\begin{array}{cc}\text { Time duration (min) } & \text { CFC/ml } \\ 0 & 1.86 \times 10^{7} \\ 20 & 1.056 \times 10^{5} \\ 40 & 7.26 \times 10^{4} \\ 60 & 6.43 \times 10^{4} \\ 80 & 5.78 \times 10^{4} \\ 100 & 4.50 \times 10^{4} \\ 120 & 2.22 \times 10^{4} \\ 140 & 9.60 \times 10^{3} \\ 160 & 7.4 \times 10^{3}\end{array}$

\section{B. Bioassay UV Mutated Strains of AKl isolate:}

The UV mutated AK1 colonies were subcultured and bioassayed by agar gel disc diffusion method against S.aureus. The antimicrobial activity of mutated strain patch numbered as 24 and 23 showed higher activities and number 69 showed lower activity (Fig 1).
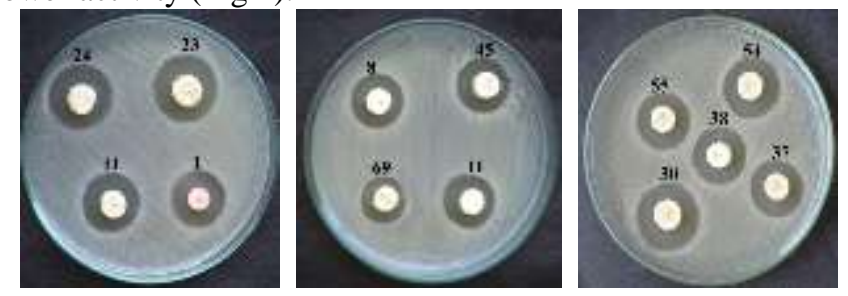

Fig 1. Antibacterial Activity Of Ak1-UV Mutated Strain (1 - Wild Type; Others Were UV Mutated Strains).

\begin{tabular}{|c|c|c|}
\hline \multicolumn{3}{|c|}{ MUTAGENESIS } \\
\hline $\begin{array}{l}\text { Time duration } \\
\text { (seconds) }\end{array}$ & $\begin{array}{c}\text { Patch } \\
\text { numbers }\end{array}$ & $\begin{array}{l}\text { Inhibition zone } \\
\qquad(\mathrm{mm})\end{array}$ \\
\hline 0 & 1 & 19 \\
\hline \multirow[t]{2}{*}{60} & 45 & 19 \\
\hline & 69 & 15 \\
\hline \multirow[t]{2}{*}{80} & 8 & 18 \\
\hline & 11 & 20 \\
\hline \multirow[t]{2}{*}{100} & 20 & 19 \\
\hline & 21 & 20 \\
\hline \multirow[t]{3}{*}{120} & 24 & 24 \\
\hline & 23 & 24 \\
\hline & 37 & 20 \\
\hline \multirow[t]{3}{*}{140} & 38 & 21 \\
\hline & 30 & 23 \\
\hline & 60 & 19 \\
\hline \multirow[t]{2}{*}{160} & 55 & 20 \\
\hline & 54 & 22 \\
\hline
\end{tabular}

\section{NTG Mutagenesis:}

The AK1 isolate was also mutated by NTG, a chemical mutagen. The rate of mutation was parallel with the increasing dosage and later by a decline. The survival curve showed decreased phase. The mutants differed from the wild parent in reduced growth rates, changes in the shape and size of the colony, sporulation level, antibiotic activity and variation in the colour of the mycelium. The survival ratio of AK1 NTG mutation was tabulated (Table. IV).

TABle IV: Survival CounT OF AK1 IsOLATE AFTER NTG TREATMENT
$\begin{array}{cc}\text { Time duration (min) } & \text { CFC/ml } \\ 0 & 1.86 \times 10^{7} \\ 15 & 4.30 \times 10^{6} \\ 30 & 3.56 \times 10^{6} \\ 45 & 2.76 \times 10^{6} \\ 60 & 1.27 \times 10^{6} \\ 75 & 6.0 \times 10^{5} \\ 90 & 2.6 \times 10^{5}\end{array}$

\section{NTG Mutagenesis Bioassay:}

The NTG mutated AK1 colonies were subcultured and bioassayed by agar gel disc diffusion method against $S$. aureus. The antimicrobial activity of mutated strains resulted in no variations in their wild type activity. But the strain patch numbered as 24 showed lower activity (Fig 2). 

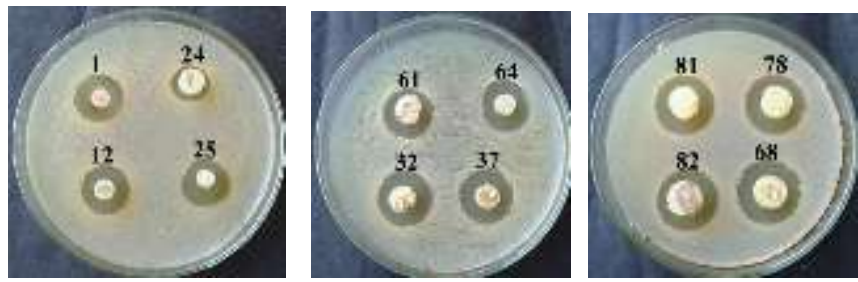

Fig 2. Antibacterial Activity Of Ak1-Ntg Mutated Strain (1 - Wild Type; Others Were Ntg Mutated Strains)

The bioassay of AK1 mutated strains were tabulated (Table V).

\begin{tabular}{|c|c|c|}
\hline \multicolumn{3}{|c|}{ MUTAGENESIS } \\
\hline $\begin{array}{l}\text { Time Duration } \\
\text { (min) }\end{array}$ & $\begin{array}{c}\text { Patch } \\
\text { Numbers }\end{array}$ & $\begin{array}{l}\text { Inhibition } \\
\text { Zones (mm) }\end{array}$ \\
\hline \multirow[t]{2}{*}{0} & 1 & 19 \\
\hline & 81 & 19 \\
\hline \multirow[t]{3}{*}{15} & 82 & 19 \\
\hline & 84 & 20 \\
\hline & 68 & 21 \\
\hline \multirow[t]{3}{*}{30} & 69 & 20 \\
\hline & 78 & 19 \\
\hline & 54 & 20 \\
\hline \multirow[t]{4}{*}{45} & 59 & 19 \\
\hline & 61 & 17 \\
\hline & 64 & 18 \\
\hline & 32 & 20 \\
\hline \multirow[t]{3}{*}{60} & 37 & 20 \\
\hline & 50 & 20 \\
\hline & 23 & 21 \\
\hline \multirow[t]{3}{*}{75} & 24 & 15 \\
\hline & 25 & 20 \\
\hline & 12 & 20 \\
\hline \multirow[t]{2}{*}{90} & 14 & 20 \\
\hline & 16 & 21 \\
\hline
\end{tabular}

\section{DISCUSSION}

In Actinomycetes, a close relationship between secondary metabolism and cell differentiation has been established and exogenous metabolites can positively regulate the production of antibiotics (Gohar and El-Naggar, 2001). The present study explored the utility of Actinomycetes in the war against microbial infection. The pharmaceutical industries were interested in the true source of secondary metabolites from potent natural sources like Actinomycetes. Shikha et al., (2007), reported 1.44 fold alkaline protease productions by Bacillus panththenticus. However, Dutta and Bannerjee, (2006) observed a 2.5 fold increase in alkaline protease productivity by UV mutant Pseudomonas sp. JNGR 242.

Mutation and screening of industrially useful microorganisms are very important for the successful development of various strains which are required in the fermentation industry (Dutta and Bannerjee, 2006). Similar trend of decrease in survivability with increase in exposure time has also been reported by some other investigators (Shikha et al., (2007), Nadeem M, et al., (2010), Mukhtar and Haq, 2008). All these findings indicated that the survivability of parent strain depended on the nature of the microorganism, treatment period and the type of mutagens (Javed et al., 2013).

This study demonstrated that the Actinomycetes has potential microbial demulsify and could be the ever remedy for infectious diseases. As stated earlier, Actinomycetes have provided many important bioactive compounds of high commercial value and continue to be routinely screened for new bioactive substances (Nanjwade et al., 2010). The phenotypic relatedness could be also used to eliminate duplicate actinomycete strains in the future by a microbial screening programme. Further investigations should definitively answer the question of how secondary metabolism and aerial mycelium development are regulated in this strain (Gohar and El-Naggar, 2001).

\section{REFERENCES}

[1] P. Bevan, H. Ryder and I. Shaw. (1995). Identifying small molecule lead compounds: the screening approach to drug discovery. Trends Microbiol 7(2): 124-136. http://dx.doi.org/10.1016/s0167-7799(00)88916-7

[2] S. Javed, M. Meraj, S.A. Bukhari, S. Irfan R,Mahmood. (2013). Hyper-production of Alkaline Protease by Mutagenic Treatment of Bacillus subtilis M-9 using Agro industrial Wastes in Submerged Fermentation. J Microb Biochem Technol 5: 74-80

[3] Freire-Moran Laura, BoAronsson, Vhris Manz, Inge C. Gyssens, Anthony D. So, Dominique L. Monnet and Otto Cars. (2011). Critical shortage of new antibiotics in development against multidrug-resistant bacteria-Time to react is now. Drug Resist Updat: 14: 118-124. http://dx.doi.org/10.1016/j.drup.2011.02.003

[4] H.W. Boucher, G.H. Talbot, J.S. Bradley, J.E. Edwards, D. Gilbert, L.B. Rice, M. Scheld, B. Spellberg, J. Bartlett. (2009). Bad bugs, no drugs: no ESKAPE! An update from the Infectious Diseases Society of America. Clin. Infect. Dis. 48, 1-12. http://dx.doi.org/10.1086/595011

[5] H. Hu, and K. Ochi. (2001). Novel approach for improving the productivity of antibiotic-producing strains by inducing combined resistant mutations. Appl. Environ. Microbiol. 67:1885-1892. http://dx.doi.org/10.1128/AEM.67.4.1885-1892.2001

[6] M.H. Medema, M.T. Alam, R. Breitling, E. Takano. (2011). The future of industrial antibiotic production: from random mutagenesis to synthetic biology. Bioeng Bugs. 2:230-233. http://dx.doi.org/10.4161/bbug.2.4.16114

[7] B.K. Nanjwade, S. Chandrashekhara, M. Ali, S.G. Shamarez, Prakash and V.M. Fakirappa. (2010). Isolation and Morphological Characterization of Antibiotic Producing Actinomycetes. Tropical Journal of Pharmaceutical Research; 9 (3): 231-236

[8] K.S. Kumar, S. Anuradha, G.R. Sarma, Y. Venkateshwaralu, V. Kishan. (2012). Screening, Isolation, Taxonomy and fermentation of an antibiotic producer Streptomyces xinghaiensis from soil capable of acting against linezolid resistant strains. Indian Journal of Experimental Biology. 50: 718-728

[9] S.B. Ilic, Z.B. Konstantinovic, M.L. Todorovic, V.B. Lazic and V.B. Veljkovic. (2007). Characterization and antimicrobial activity of the bioactive metabolites in Streptomyces isolates. Microbiol 76(4): 421-428.

http://dx.doi.org/10.1134/S0026261707040066

[10] C.L. Doumbou, K. Michelle. Hamby Salove, L. Don. Crawford and Carole Beaulieu. (2001). Actinomycetes, promising tools to control plant diseases and to promote plant growth. Phytoprotection., 82: 85-102 http://dx.doi.org/10.7202/706219ar

[11] J.M. Bapela, V. Kuete., E.D. Toit and M.J.J. Meyer. (2008). Fertilization-induced changes in growth parameters and antimycobacterial activity of Eucleanatalensis (Ebenaceae). South African. J. Bot., 74: 244-250. http://dx.doi.org/10.1016/j.sajb.2007.11.011

[12] Y. Tanaka, S. Omura. (1993). Agro active compounds of microbial origin. Annu Rev Microbiol. 47: 57-87. 
http://dx.doi.org/10.1146/annurev.mi.47.100193.000421

[13] M.R Rani, N.N. Prasad, K.R.S. Sambasivarao. (2012). Optimization of cultural conditions for the production of alkaline protease from a mutant Aspergillus Flavus AS2. Asian J Exp Biol Sci 3: 565-576.

[14] N.K. Gogoi, R.N.S. Yadav, P.K. Dutta and G.N. Bordoloi. (2005). Studies on antimicrobial activity of Actinomycetes strains isolated from Majuli, a river island. Ind. J. microbiol., 45: 231-234.

[15] A. Lazzarini , L. Cavaletti, G. Toppo, and F. Marinelli. (2000). Rare genera of Actinomycetes as potential producers of new antibiotics. Anton van Leeuwenhoek., 78: 399-405. http://dx.doi.org/10.1023/A:1010287600557

[16] D. Thakur, A. Yadav, B.K. Gogoi, and T.C. Bora. (2007). Isolation and screening of Streptomyces in soil of protected forest areas from the states of Assam and Tripura, India, for antimicrobial metabolites. J. Mycol. Med., 17: 242-249. http://dx.doi.org/10.1016/j.mycmed.2007.08.001

[17] Y. Zhang, LiH \& W. Lu. (1993). Taxonomic study on strain 1254 and its mutant 113. Acta Microbiologica Sinica. 33 (1):13-21.

[18] J. Holmalahti, O. Raatikainen \& A. Von-Wright. (1993). Transformable mutants of a biopesticide strain Streptomyces griseoviridis K61. Journal of Industrial Microbiology. 11 (3):193-198. http://dx.doi.org/10.1007/BF01583722

[19] T. Held \& H.J. Kutzner. (1991). Genetic recombination in Streptomyces michiganensis DSM40 015 revealed three genes responsible for the formation of melanin. Journal of Basic Microbiology 31(2): 127-134. http://dx.doi.org/10.1002/jobm.3620310211

[20] P. Amade, M. Mallea \& N. Bouaicha. (1994). Isolation, structural identification and biological activity of two metabolites produced by Penicillium olsoniibainier and Sartory. Journal of Antibiotics 47(2):201-207. http://dx.doi.org/10.7164/antibiotics.47.201

[21] M. Gohar Yousry and Y. El-Naggar Moustafa. (2001). Induction of sporulation and antibacterial activity in the aerial mycelium negative mutants of Streptomyces nasri. Egyptian Journal of Biology, 3: 23-35

[22] A. Shikha, Sharan, N.S. Darmwal . (2007). Improved production of alkaline protease from a mutant of alkalophilic Bacillus pantotheneticus using molasses as a substrate. Biores Tech 98: 881-885. http://dx.doi.org/10.1016/j.biortech.2006.03.023

[23] J.R. Dutta, R. Bannerjee (2006). Isolation and characterization of a newly isolated Pseudomonas mutant for protease production. Braz Arch Biol Tech 49: 37-47. http://dx.doi.org/10.1590/S1516-89132006000100005

[24] M. Nadeem, J.I. Qazi, S. Baig. (2010). Enhanced production of alkaline protease by a mutant of Bacillus licheniformis $\mathrm{n}-2$ for dehairing. Braz Arch Biol Tech 53: 1015-1025 http://dx.doi.org/10.1590/S1516-89132010000500003

[25] H. Mukhtar, I. Haq. (2008). Production of alkaline protease by Bacillus subtilis and its applications as deplating agents in leather processing. Pak J Bot 40: 1673-1679.

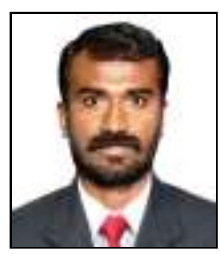

Dr.P.Ashok Kumar has Life Memberships in ASM, SFAM, ECCMID, ISALS, IAAM, MBAI, RSC. I was born in Srivilliputtur, Tamil Nadu (TN), India in 1977. I was awarded $\mathrm{PhD}$ in Marine Biotechnology-Microbiology (Interdisciplinary) from Manonmaniam Sundaranar University, Tirunelveli, TN, India during March 2008. My M.Sc was in Marine Biotechnology from Manonmaniam Sundaranar University, Tirunelveli, TN, India in 2001 and B.Sc Microbiology from Madurai Kamaraj University, Madurai, TN, India in 1999. My area of specialization is in Microbial Technology.

The author started his career as Lecturer in Biotechnology in MCAS, Rasipuram, TN, India in 2005. Soon he was appointed as Assistant Professor in Biotechnology at AAIDU, Allahabad, India in 2006. He has visited Malaysia, Iran, Tunisia, Ethiopia, Eritrea, Yemen, Bahrain and Dubai on Academic and Research trips. He has published numerous articles in national and international peer reviewed journals. $\mathrm{He}$ attended an International Training in Molecular Biology in Tehran, Iran in 2008. He joined as Reader inMicrobiology, Faculty of Science, SSU, Sokoto, Nigeria in 2013, and currently was promoted as HEAD of the Department of Microbiology, SSU, Sokoto, Nigeria. Additionally he holds the responsibility as Director, Division of General Studies. His major field of research includes
Multiple Antibiotic Resistance Profiling and Medicinal Plant Research, Dr.P.Ashok Kumar, was awarded Best Teacher for the 2008-2009 session in MVJCE, Bangalore, India, Best Oral Presentation Award in $2^{\text {nd }}$ International Conference on Biotechnology, held at University of Tehran, Tehran, Iran, Nov 2008 and Best Poster Presentation Award in the National Academy of Sciences India \& CFTRI - Mysore, December 2007. To his credit, he has 26 publications in peer reviewed journals. 